\title{
PRÁCTICAS Y REPRESENTACIONES VINCULADAS A LA PRODUCCIÓN Y CONSUMO DE FRUTOS DE ESPECIES FORESTALES DEL BOSQUE NATIVO: REFLEXIONES A PARTIR DE LA RECONSTRUCCIÓN DE LAS TRAYECTORIAS SOCIALES DE LA ALGARROBA EN CHACO FORMOSEÑO.
}

En memoria de Zulma Acuña. Extraordinaria mujer y un ejemplo de vida. Gracias por tu amistad, tus enseñanzas y tus cuidados. Fue un privilegio haberte conocido. Te extrañaremos siempre...

\section{Sebastián CARENZO * Ludmila QUIROGA **}

\section{Resumen}

Este trabajo propone aportar a la comprensión de un fenómeno que cobra cada vez más relevancia entre los grupos campesinos e indígenas que habitan el Gran Chaco: la

\footnotetext{
Doctor en Antropología Social. Investigador adjunto CONICET. Sección de Antropología Social, Instituto de Ciencias Antropológicas, FFyL-UBA.

** Licencida en Antropóloga Social. Becaria Doctoral - UBA. Sección de Antropología Social, Instituto de Ciencias Antropológicas, FFyL-UBA.

Fecha de recepción del artículo: Febrero 2014

Fecha de evaluación: Mayo 2014
} 
homogenización y empobrecimiento del patrón alimentario de estas poblaciones. Desde una perspectiva de antropología alimentaria, desarrollamos un estudio de caso sobre las prácticas y representaciones vinculadas a la producción y consumo frutos del algarrobo (Prosopis Alba). La reconstrucción de las trayectorias sociales asociadas a este alimento, se revela como un dispositivo significativo para dar cuenta de la dinámica de transformaciones evidenciadas en su producción, distribución y consumo durante los últimos tres siglos.

Palabras clave: Antropología alimentaria, desarrollo rural, soberanía alimentaria, algarroba, gran chaco.

\begin{abstract}
This paper aims to contribute to the understanding of a phenomenon that is becoming more relevant to the peasants and indigenous groups that inhabit the Gran Chaco: homogenization and impoverishment of the dietary pattern of these populations. From an anthropology of food perspective, we developed a case study on the practices and representations linked to the production and consumption of Algarroba fruits (Prosopis Alba). The reconstruction of social trajectories associated with this food, is revealed as a significant device to account for the dynamics of transformations evidenced on its production, distribution and consumption over the past three centuries.
\end{abstract}

Key words: Anthropology of food, rural development, food sovereignity, algarroba, gran chaco.

\title{
Resumé
}

Cet travail se propose contribuer à la compréhension d'un phénomène qui porte de plus en plus importance entre les groupes paysans et indigènes qui habitent le Grand Chaco: l'homogénéisation et appauvrissement du patron alimentaire de ces populations. À partir d'une approche de l'anthropologie alimentaire, on developpe une étude de cas sur les pratiques e représentations relatives à la production et consommation de fruits de caroubier (Prosopis $A l b a)$. La reconstruction des trajectoires sociales associe à c'est nourriture, apparaît comme un dispositif relevant pour mettre en évidence la dynamique des transformations évidences sur sa production, distribution et consommations pendant les trios derniers siècles.

Mots-clés: Anthropologie alimentaire, développement rural, souveraineté alimentaire, algarroba, Gran Chaco. 


\section{Introducción}

Las profundas transformaciones que se vienen desarrollando en la estructura territorial de la región del Chaco formoseño, han puesto de manifiesto tensiones en la práctica agro-ganadera local, vinculadas al avance de la frontera agropecuaria tal como evidencia una profusa literatura (Giarraca et.al., 2001; Teubal, 2006,). Las consecuencias sociales y ecológicas de este proceso también han sido exhaustivamente documentadas, básicamente: alta concentración de la propiedad rural, acelerado proceso de deforestación de bosques nativos, agriculturización y ganadería de trópicos sobre tierras forestales. En particular desde la antropología social se han aportado evidencias suficiente respecto a cómo estos procesos han reconfigurado los límites y posibilidades de las estrategias domésticas de producción y reproducción en poblaciones de pequeños productores criollos y pueblos originarios (Balazote y Radovich, 2000; Trinchero, 2000; Gordillo, 2010; Braticevic, 2009).

La investigación que sostiene este artículo se realizó con un grupo de 50 familias de pequeños productores "criollos" que habitan en las inmediaciones de la localidad de Ibarreta, en el centro-oeste de la provincia de Formosa. Se encuentran asentados en "colonias" agrícolas orientadas hacia un sistema productivo doméstico, basado en la ganadería y agricultura en pequeña escala, complementado con prácticas de caza-recolección destinada a la subsistencia. El grueso de la producción predial se destina al autoconsumo, y los excedentes son comercializados. El acceso a maquinaria e infraestructura productiva es muy limitado y sus capacidades productivas y reproductivas se ven debilitadas por la venta -temporaria o permanente- de la fuerza de trabajo de sus integrantes. Sumado a esto, se observa una dependencia cada vez mayor de los ingresos extraprediales, que producen una creciente monetarización de estas economías domésticas, aumentando su dependencia del mercado. Asimismo, es necesario tener en cuenta las migraciones hacia centros urbanos de gran parte de la población de jóvenes en edades productiva, con la consecuente apropiación y resignificación de nuevos estilos de consumo (Carenzo, 2004 y 2006; Quiroga, 2010).

1 Es preciso aclarar que utilizamos el término criollos como una categoría nativa, ya que en esta región del país esta categoría que refiere a una heterogénea construcción poblacional conformada por migrantes y su descendencia, provenientes de provincias limítrofes (Chaco, Corrientes, Santiago del Estero y Salta), así como también de Paraguay (Carenzo, 2004). 
Siguiendo está línea de análisis, Uno de los fenómenos que evidencia en forma más significativa esta transformación, se relaciona con el proceso de creciente homogeneización y empobrecimiento que evidencia el patrón alimentario de estos grupos indígenas y campesinos del Gran Chaco, asentados en poblaciones localizadas en zonas rurales y periurbanas, históricamente vinculadas a la autoproducción de alimentos. La literatura especializada en temas de alimentación desde una perspectiva sociocultural y situada en el contexto latinoamericano, viene señalando que entre los procesos relacionados más frecuentes con está problemáticas se mencionan: la pérdida progresiva de saberes y prácticas vinculadas al patrimonio alimentario local y regional; el reemplazo de alimentos provenientes de la caza-recolección o de la autoproducción, por bienes industrializados de consumo masivo; el desequilibrio en la relación en la ingesta de proteínas/carbohidratos a favor de estos últimos; y la mayor incidencia de la malnutrición y desnutrición entre otros desequilibrios metabólicos asociados a la alimentación (Arenas, 2003; Torres, 1999; Charpentier, 1998; Garufi, 1997).

Por otra parte resulta importante destacar que los alimentos silvestres de origen vegetal (que no se derivan de sistemas productivos de tipo agrícola) resultan un aporte importante en las prácticas de aprovisionamiento domésticas, tanto en épocas históricas (Rosenzvaig, 1996; Vitar, 1997; Noli, 1999; Bonnin y Laguens, 2000) como en la actualidad (Maranta, 1987; Gonzalez, 2001; Arenas, 2003; Pinotti, 2004; Torres, Santoni y Romero, 2007)

Partiendo de esta paradoja, nos proponemos recuperar el proceso histórico de cambio (social, cultural y económico) que han sufrido estás poblaciones indígenas y criollas locales del chaco formoseño, centrándonos en la trayectoria alimentaria de una de las especies emblemáticas de los bosques nativos de esta región. El Algarrobo Blanco (Prosopis alba) es reconocido en todo el país por la nobleza de su madera oscura y resistente, pero en la región chaqueña esta leguminosa es además apreciada por su abundante fructificación, siendo uno de los insumos clave que dio forma a patrones alimentarios locales de pueblos originarios y campesinos criollos en esta region. De tal modo buscamos indagar sobre el devenir histórico de prácticas y representaciones asociadas al aprovechamiento de recursos alimenticios del bosque nativo, en particular las vainas de color amarillo, conocidas con el nombre de "algarroba", que presentan un alto poder nutritivo y un agradable sabor dulce ${ }^{2}$. Este artículo es resultado de nuestra labor

2 Según informe técnico elaborado por la Facultad de Agronomía (UBA) con muestras de harina provenientes de Ibarreta, Formosa: Valores obtenidos mg/ gr de materia seca: Calcio 1,4; 
en $\mathrm{ONG}^{3}$ dedicada a proyectos de desarrollo rural centrada en el manejo sustentable de los bosques nativos y la recuperación y puesta en valor de prácticas productivas y alimentarias que aprovechan los recursos silvestres del bosque nativo.

\section{Orientaciones respecto del marco conceptual y metodológico empleados en este trabajo}

Los encuadres teóricos y conceptuales que nutrirán nuestro estudio son, por una parte, los aportes de la Antropología Alimentaria que propone abordar la problemática de la alimentación, desde una mirada holística que abarque sus múltiples dimensiones: biológica, ecológicas, económica, política, social, cultural y simbólica. El análisis de hábitos, patrones alimentarios $\mathrm{y} / \mathrm{o}$ prácticas productivas asociados con determinados alimentos, requiere comprender a los alimentos no sólo como portadores de nutrientes, sino también recuperado los significados culturales y sociales que encarnan en un contexto históricamente determinado. (Contreras, 1993; Fischler, 1995; Contreras y Arnaiz, 2003; Piaggio y Solans, 2009 y Quiroga, 2010).

De esta manera, es preciso reconocer la existencia de diferentes racionalidades materiales, sociales y culturales que se articulan y se interrelacionan (y que en algunos casos pueden tener un carácter contradictorio), desde donde se definen las pautas alimentarias de una sociedad. Asimismo, podemos agregar que es preciso reconocer que estas racionalidades no siempre se corresponden con la filosofía utilitarista que hoy domina el pensamiento occidental. Es decir, la clasificación de aquello que es alimento, de lo que no lo es, no siempre responde a la elección de un "individuo racional" que realiza un cálculo de costo-beneficio en términos nutricionales y/o económicos. Mucho de lo que comemos no responde a una motivación utilitaria, no solo

Hierro

0,07 ; Potasio

0,9

; Sodio

0,13

; Zinc

0,015

. FA-UBA. 16/06/2005

3 Se trata del Grupo de Estudios sobre Ecología Regional (GESER): www.geser.org.ar, en donde trabajamos desde 2003 hasta 2009. 
comemos un alimento porque es nutritivo, equilibrado, económico o de calidad. Aquí entran en juego cuestiones relacionadas con "el gusto": nos gusta, nos da placer, nos hace sentir parte de un grupo, o nos conecta con determinados valores, representaciones simbólicas, recuerdos y modos de entender y actuar en la vida. Nada de esto tiene que ver con el cálculo de unidades calóricas o unidades monetarias, y sin embargo permite comprender buena parte de nuestras prácticas relacionadas con la alimentación.

Como evidencia Pinotti (2004) la comprensión de los sistemas de preferencias vinculados a la alimentación, es indisociable del análisis de las prácticas y representaciones presentes en la cultura de cada grupo, construidas a través de un complejo proceso histórico que da cuenta de la dinámica de relaciones que los grupos humanos establecen entre sí, con otros grupos y con la naturaleza. En este sentido, el análisis del "patrón alimentario" de un pueblo no solo debe reconstruir el conjunto de bienes y elementos de la naturaleza que son considerados "comida", sino que debe incluir una reflexión sobre las prácticas materiales (tecnologías de producción, técnicas de preparación, espacios de sociabilización, distribución y consumo, etc.), así como también, debe abordar el conjunto de relaciones sociales, normas y representaciones simbólicas que intervienen en la regulación social de estas prácticas. En particular el analisis del patrón alimentario de las poblaciones del chaco formoseño, requiere abordar la dinámica de transformaciones en el tiempo. Tanto en términos de los componentes materiales que lo conforman (abandono, sustitución e incorporación de alimentos), como en cuestiones mucho menos tangibles como las preferencias relacionadas al "gusto", los ámbitos de sociabilización relacionados con el hecho de intercambiar y compartir el alimento, y las representaciones sociales respecto de quiénes, cómo y por qué participan en los actos de alimentación de un determinado grupo social ${ }^{4}$.

En función de ello, trabajaremos desde la categoría de Trayectoria aplicada al hecho alimentario. Entendiendo este concepto como el continuo de acontecimientos significativos relacionados con el fenómeno social en cuestión (FQS, 2004). Somos consientes que esta categoría ha sido trabajada desde las ciencias sociales en referencia a la sucesión no lineal de

4

Esto se debe a que las personas se identifican con un grupo social según lo que comen, como lo comen, con quienes comparten los alimentos y los métodos de abastecimiento y producción a los que tienen acceso; articulándose de esta manera los sentimientos de pertenencia a un grupo, la búsqueda de prestigio y estatus social (Contreras, 1993) 
experiencias vitales de los sujetos sociales ${ }^{5}$. Sin embargo consideramos que su aplicación al análisis que proponemos es pertinente en términos de dar cuenta de la dinámica de transformaciones en las prácticas y representaciones sociales vinculadas con el proceso de producción, distribución y consumo de algarroba. En particular elegimos trabajar sobre la trayectoria de este alimento, ya que condensa múltiples aspectos vinculados a la vida material y simbólica de las poblaciones del chaco argentino. En tal sentido, nuestro objeto no apunta al estudio de la algarroba en sí, sino que nos centraremos en la dinámica de relaciones que los distintos grupos sociales han establecido con este alimento a lo largo del proceso histórico, y en diferentes contextos socio-económicos. Asimismo, esta perspectiva permite reconstruir las ambigüedades, los contrastes, las marchas y contramarchas en la valorización social de los alimentos, aspectos que no suelen ser abordados cuando se trabaja desde el concepto de "patrón alimentario" y desde una visión estática y sincrónica de la cultura. Los distintos bienes de la naturaleza que son apropiados y transformados en alimentos por pueblos y comunidades, no siempre son categorizados y/o valorizados de igual modo, o en base a los mismos criterios. Estos son permanentemente resignificados a partir de los condicionantes estructurales o coyunturales presentes en los diferentes contextos socio-históricos. Incluso este proceso de significación diferenciada ocurre a nivel intra-comunitario, por ejemplo entre los distintos grupos etarios y/o socio-económicos que reagrupan a sus integrantes. Esto implica el pasaje de una mirada de la cultura alimentaria de un pueblo como algo estático y cristalizado, a una comprensión más profunda de su compleja y permanente dinámica. Siguiendo el sentido que Graffigna (2005:3) confiere al concepto de trayectoria, podemos entenderla más bien como un "recorrido" sin direccionalidad establecida a priori, en el cual nos interesa señalar justamente las variaciones y cambios en la dirección de los procesos involucrados. Esto implica buscar principalmente las rupturas y las discontinuidades en dicho recorrido, ya que creemos que nos indican aquellos hitos o momentos significativos en los cuales se producen cambios en las prácticas y representaciones asociadas a un determinado elemento o proceso presente en la cultura alimentaria que estamos analizando. Son estos momentos donde se entrecruzan múltiples dimensiones -no sólo la económica-, donde podemos encontrar las claves analíticas para comprender los procesos en juego. Sin embargo, cabe señalar que muchas veces estos cambios en las trayectorias se desarrollan sin presentar rupturas profundas, sino como

$5 \quad$ El sociólogo francés Pierre Bourdieu (1988) señala al respecto que los individuos recorren en su experiencia vital un continuo de experiencias que van trazando estos itinerarios o trayectorias (a veces más previsibles, a veces más aleatorias) que se construyen simultánea y pluralmente en múltiples dimensiones: familiar, social, laboral, política, religiosa, cultural. 
consecuencia de la sumatoria de cambios casi imperceptibles que le dan un marco de continuidad a lo largo del tiempo, y que solo pueden constituirse en objeto de reflexión al analizar estos procesos desde una perspectiva histórica

En términos metodológicos, la reconstrucción de estas trayectorias la realizamos a partir de un abordaje etnográfico, que combina instancias de análisis complementarias: Por una parte la identificación, sistematización y análisis de fuentes secundarias: principalmente fuentes bibliográficas sobre ecología de las especies forestales nativas, etnobotánica indígena y criolla, documentos históricos, recetarios de comidas tradicionales, etc. Esto nos permite reconstruir las etapas históricas del uso de la algarroba y situar algunos recorridos desde sus primeras manifestaciones hasta el presente. Por otra parte, el desarrollo del trabajo de campo antropológico, en donde realizamos entrevistas no estructuradas y empleamos técnicas de observación participante para la elaboración de registros de campo, implicó profundizar nuestra investigación sobre un fenómeno en particular: la recolección de la algarroba en la localidad de Ibarreta (Dto. Patiño, Provincia de Formosa) desde el 2003 al 2009. Este segundo enfoque de la investigación resultó sumamente importante ya que permitió situar el análisis de las trayectorias en relación a la experiencia vital de los sujetos sociales involucrados, que transcurre en un doble vínculo entre procesos estructurales e historias personales y familiares (Op.cit, 2005).

\section{La "algarroba" como recurso estratégico para una propuesta de soberanía alimentaria.}

En nuestro país el nombre "Algarrobo" resulta una denominación genérica aplicada a diferentes especies forestales pertenecientes al genero Prosopis, entre los que podemos mencionar Prosopis alba, Prosopis chilensi (ambos denominados algarrobo blanco), Prosopis flexuosa (algarrobo dulce) y Prosopis nigra (algarrobo negro). Los autores Demaio et.al. (2002) especifican que se trata de especies arbóreas nativas emparentadas. Estas especies leñosas de porte mediano se distribuyen en las regiones central, cuyo, norte y este de nuestro país. Una característica común a estas especies de leguminosas es su abundante fructificación, brindando anualmente gran cantidad de vainas de alto poder nutritivo, que se denominan localmente "algarroba". Las vainas de Prosopis alba son especialmente apreciadas debido a su contenido en azúcares, presentando además un importante valor nutricional.

La denominación "algarrobo" se generalizó en nuestro territorio a partir del siglo XV como consecuencia de la conquista española. Estos últimos encontraron una gran similitud morfológica y biológica entre los Prosopis americanos y otra especie característica del 
mediterráneo europeo la Ceratonia siliqua, a la que llamaban precisamente "algarrobo", a partir de una derivación lingüística del nombre moro por el cual se conocía a esta especie: "al carob" que significaba "El árbol", en alusión a la importancia que esta especie y sus frutos presentaban en la vida de estos pueblos. Más allá de la confusión aportada por los españoles, existe una coincidencia significativa. Para los pueblos originarios que vivían en esta parte del continente, la denominación nativa para estos árboles también reflejaba la importancia que distinguía a esta especie en particular entre la diversidad forestal característica de los bosques chaqueños: las dos lenguas nativas más generalizadas en este territorio al momento de la conquista lo denominaban "Takku" (lengua quichua) e "Ibopé" (lengua guaraní). La voz quichua también significaba "El árbol", mientras que su par guaraní refería a aquel "árbol que ha sido puesto en el camino para comer". Esta trascendencia expresada en lo lingüístico reflejaba el lugar central que esta especie ha tenido y aún tiene en el desarrollo de los sistemas de vida de pueblos originarios y grupos criollos de la región chaqueña.

En la actualidad, el algarrobo continúa siendo una de las especies más representativas de los bosques nativos de la región Chaqueña, junto con otras especies forestales de gran valor, como quebracho colorado (Schinopsis balansae) y quebracho blanco (Aspidosperma quebracho blanco), itín (Prosopis kuntzei), mistol (Ziziphus mistol) y palo santo (Bulnesia sarmientoi). Sin embargo, estos ambientes de bosques nativos de monte están siendo amenazados por la sobreexplotación, tanto de los obrajes dedicados a la extracción de maderas nobles, como por el avance de la frontera agropecuaria, que amenaza la conservación de grandes extensiones de bosques nativos, debido al reemplazo de ecosistemas de monte, por agrosistemas dedicados al cultivo intensivo de oleaginosas destinadas a la exportación.

Los principales afectados por este proceso son los pueblos originarios y comunidades de pequeños productores criollos, que han desarrollado modos de vida que dependen de la existencia y disponibilidad de estos ambientes. Los bosques nativos en general y en especial los algarrobales proveen de una variedad de recursos naturales y servicios ambientales fundamentales para garantizar la existencia y reproducción de sus sistemas de producción y consumo. Sintéticamente podemos mencionar que estos árboles contribuyen fuertemente al mantenimiento del equilibrio ecológico regional, ya que mejoran los suelos, favoreciendo la fijación del nitrógeno y colaborando en la retención de agua; proveen de alimento, refugio y sombra a la fauna silvestre y doméstica; protegen las pasturas y cultivos con su sombra, en una región donde la sequía invernal contrasta con temperaturas superiores a los 50 grados durante la lluviosa temporada estival (Galera, 2000). 
En este contexto, signado por la implementación en la región de un modelo de producción primaria que resulta depredador en lo ambiental, concentrador en lo económico y excluyente en lo social; se hace prioritario volcar los esfuerzos hacia el desarrollo de alternativas productivas centradas en el manejo forestal del bosque nativo. Un eje central en estas propuestas consiste en el aprovechamiento sustentable de los "recursos forestales no maderables", que incluye todas aquellas producciones que pueden obtenerse de los árboles sin comprometer la sustentabilidad del recurso. Esto implica comprender la importancia de mantener los ecosistemas de bosques nativos, no solo en función del rol que presentan en la regulación los procesos ambientales básicos que mencionamos anteriormente, sino también en razón del potencial económico que hoy en día presentan las producciones alternativas a la ganadería y la agricultura. Esto implica posicionarse desde el enfoque de la soberanía alimentaria, recuperando el peso que presenta hoy en día esta categoría política tanto en las demandas de las organizaciones de productores alrededor del mundo, como por ejemplo la Vía-Campesina ${ }^{4}$. Como así también, nos interesa recuperar el lugar que está alcanzando en las agendas políticas nacionales y en las políticas de las Agencias de Cooperación Multilateral. La soberanía en temas de alimentación, es entendida como el derecho a la libre-determinación de los pueblos, teniendo en cuenta el derecho de los mismos a decidir y definir sus propias políticas alimentarias, estrategias de producción, distribución y consumo que garanticen el derecho a una alimentación digna y sana para toda la población, teniendo en cuenta sus preferencias en cuanto a los alimentos. Por consiguiente, las organizaciones de productores que apoyan esta ideología política, demanda a los Estados nacionales políticas que generen un rescate de los modos tradicionales de producción, así como la necesidad de que los Estados se comprometan en la democratización de las políticas públicas orientadas a la redistribución de los recursos, y el combate a las políticas neoliberales y sus ejecutores a nivel internacional, como es el caso de la Organización Mundial del Comercio OMS-. (Shiva, 2003; Domínguez et. al., 2002)

Como veremos a continuación, para las poblaciones locales del chaco sudamericano, tanto el árbol del algarrobo como los alimentos preparados con sus frutos condensan una serie de atributos de orden material y simbólico (vinculados a su carácter multipropósito, resistencia a climas rigurosos, prodigalidad de sus frutos, propiedades mágicas y curativas, entre muchas otras). Que permitieron encarar el trabajo conjunto de recuperación de su uso y puesta en valor

$4 \quad$ La Vía Campesina es movimiento internacional que fue fundado en 1993 en Bélgica. Es un movimiento internacional que impulsa el derecho a la Soberanía http://www.viacampesina.org 
conjugando las dimensiones económicas, sociales y culturales en un proceso holístico e integrador.

\section{Aportes para la reconstrucción de la trayectoria social de la algarroba}

Dado el alcance del presente trabajo no podemos desarrollar aquí una reconstrucción exhaustiva de la trayectoria social de las prácticas y representaciones vinculadas a la algarroba. Nuestra labor se limitará entonces a presentar tres momentos significativos que nos permiten dar cuenta del recorrido histórico de este alimento a través de diferentes contextos de significación que han condicionado su valorización para los distintos grupos sociales involucrados en cada caso:

- Primer Momento: La algarroba entre pueblos indígenas y conquistadores europeos en el Chaco Gualamba.

- Segundo Momento: De los saberes indígenas a los usos criollos en el centro-oeste de la provincia de Formosa.

- Tercer Momento: La algarroba entre tres generaciones de campesinos Ibarretenses.

A continuación profundizaremos en el desarrollo de cada uno de estos momentos especificados. Sin embargo, quisiéramos advertir que estas etapas están delimitadas de modo meramente orientativo, ya que no responden a un intento serio de periodización. Por el contrario queremos remarcar la imposibilidad de fijar límites precisos tanto para el comienzo o fin de un momento en particular, ya que el sentido de esta propuesta es establecer una serie de hitos que nos permitan dar cuenta de cambios significativos en las trayectorias que buscamos reconstruir.

\section{Primer Momento: La algarroba entre pueblos indígenas y conquistadores europeos en el Chaco Gualamba}

Las primeras referencias con las que contamos respecto del uso alimenticio de los frutos de la algarroba provienen de fuentes históricas sobre los pueblos originarios del llamado "chaco gualamba"7. Este espacio representaba a los ojos del conquistador europeo un "territorio indómito y salvaje", donde la rigurosidad de las condiciones climáticas y ambientales, pero

$7 \quad$ La denominación "chaco" proviene del vocablo quichua "chaku" que designaba los "espacio de caza", mientras que "gualamba" es una voz indígena chaqueña que adoptaron los jesuitas y que hacía referencia a algo "grande" (Rosenzvaig, 1996). 
principalmente la belicosidad manifiesta de las parcialidades guaycurues (que incluye a las etnias Toba, Abipón, Mocoví, Mbyá, Caduveo y Payaguá) y mataguayas (principalmente etnía Wichí), impidieron que los españoles pudieran controlarlo en su totalidad ${ }^{8}$.

Hacia fines del siglo XVIII los jesuitas intentaron establecer una serie de reducciones en la frontera oeste del chaco, en este marco algunos misioneros como Martín Dobrizhoffer y Florián Paucke, se lanzaron al estudio de las etnias chaqueñas con el objeto de lograr una mayor comprensión de su particular modo de subsistencia (Vitar, 1996). Estos textos, los primeros en los que se intenta hacer una descripción detallada y sistemática, estos pueblos hacían uso experto y cotidiano de la enorme diversidad de fauna y flora silvestres endémica. En estos escritos la algarroba es referenciada en un lugar destacado, puntualizando inclusive una importancia simbólica que la diferenciaba del resto de los alimentos nativos.

Siguiendo a Contreras (1993:10) podemos resaltar que la significación atribuida a los alimentos, no responde tanto a sus características intrínsecas, como a las asociaciones culturales que cada sociedad le asigna en un contexto histórico determinado. La selección de este momento en la trayectoria de la algarroba es significativa, ya que refleja el contraste existente entre las diferentes racionalidades puestas en juego en el violento encuentro de dos culturas diferentes.

Los modelos productivos que los europeos querían imponer en América se basaban en el desarrollo de la ganadería y agricultura en escala a partir de un patrón de asentamiento sedentario. Esto supuso la transformación de los ecosistemas (praderas y bosques en cultivos y potreros) y la utilización intensiva de unos pocos recursos (básicamente pasturas y tierra). En contraste, la relación técnico-ecológica indígena presentaba un bajo impacto en el ambiente, a la vez que hacía uso de una enorme diversidad de recursos, aspectos que eran plenamente funcionales a su dinámica de movilidad territorial (Gordillo, 2010; Rosenzvaig, 1996).

La mirada de los cronistas europeos, influenciada por la metáfora roussoniana del "buen salvaje", estaba centrada por una parte en la descripción minuciosa de la prodigalidad de los

8 Como señalan diversos autores el "chaco" representó un verdadero bastión de resistencia indígena tanto en la etapa colonial (s XVI al XVIII) como durante la posterior etapa republicana . El control efectivo sobre todo este territorio recién fue completado definitivamente en 1911 con la finalización de la llamada "campaña del chaco" por parte del ejército argentino. (Vitar, 1996; Rosenzvaig, 1996 y Trinchero, 2000) 
ecosistemas chaqueños; y por la otra en la "improductividad" de las formas de vida de los cazadores y recolectores chaqueños. La ambivalencia dominaba la escena, ya que los misioneros jesuitas los consideraban evidencia viva de un "estado de naturaleza" previo al desarrollo de la civilización y la cultura occidental, que estos pueblos solo superarían con la "ayuda" de la acción evangelizadora. Por otra parte, los funcionarios reales no veían más que hordas belicosas que ocupaban un territorio privilegiado cuyo potencial productivo era desaprovechado. Pero esto no es todo, ya que, estos modos de vida basados en el aprovechamiento del bosque como base de su alimentación y refugio, les permitían desarrollar una estrategia bélica sumamente efectiva consistente en ataques sistemáticos a las precarias urbanizaciones que los españoles trataban de establecer en la ruta Tucuman-Jujuy. El denso monte chaqueño que circundaba estos poblados establecía una frontera natural y política, donde los españoles no tenían control efectivo. Los ataques se organizaban, partían y regresaban desde un espacio que oficiaba como una "caja negra" absolutamente impredecible (Rosenzvaig, 1996).

Lo central en ambos casos es que el discurso europeo respecto de los sistemas nativos de aprovechamiento técnico-económico de los ecosistemas chaqueños, se realizaba principalmente a partir de una serie de categorías y juicios morales relacionados principalmente con el valor del esfuerzo y el trabajo. De esta forma se fue construyendo el estereotipo del "indio vago", que dominó la mirada de los colonizadores respecto del mundo indígena y que como veremos más adelante perdura aún en nuestros días. Básicamente la idea era que los indígenas no necesitaban "trabajar" para vivir, ya que la exuberante naturaleza les proveía todo aquello que necesitaban para atender sus necesidades sin mayor esfuerzo que el hecho de ir a buscarlos. Allí donde unos habían desarrollado estrategias sumamente exitosas de adaptación al medio, los otros veían el imperio de la desidia y el derroche.

\section{$\underline{\text { La recolección de algarroba }}$}

La siguiente ilustración (ver figura 1) fue elaborada por el jesuita Florián Paucke para documentar sus crónicas sobre el pueblo Mocoví. La imagen sintetiza las principales actividades que conformaban el modo de subsistencia de los pueblos chaqueños. Salvo la notoria ausencia de la pesca están representadas las actividades de caza, la recolección y el desarrollo de una agricultura en pequeña escala.

Figura 1: "No necesitan ninguna otra provisión". llustración de Florián Paucke. Banco de imágenes "Florián Paucke" 2006. Archivo General de la Provincia de Santa Fe. 


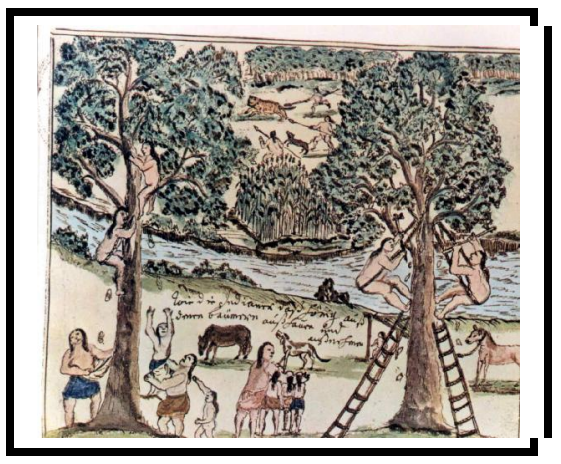

En el caso de los algarrobos, estos árboles fructificaban durante el verano donde se procedía a la recolección de los frutos, luego se guardaban secos en trojas (casetas de madera, caña y barro) que permitían su conservación para consumirlos durante el invierno, cuando arreciaba la extensa época de sequía. El valor nutricional de estos frutos les permitía atravesar esta estación crítica, donde escasean los demás alimentos.

"Habia algarrobas blancas y negras. La blanca se comía seca, cuando caía del árbol, molida en mortero o infusión. Las mujeres indias acudían al monte a recogerlas (...) Era superior utilizada como harina, que luego se amasaba con agua y formaba un pan que endurecía "como piedra". Los europeos no lo usaban como comida sino como remedio para la piedra o mal de orina, también se la daban a los tísicos" (Rosenzvaig, 1996:190-191).

Estas prácticas resultaban fundamentales para asegurar la alimentación del grupo, ya que la abundancia de estos recursos en los densos montes chaqueños permitía su aprovechamiento respetando el patrón de movilidad que caracterizaba su modo de subsistencia (durante el invierno -época seca- se desplazaban hacia los grandes ríos y en el verano con la llegada de las lluvias se adentraban en los bosques centrales).

La llegada de los misioneros jesuitas puso en evidencia que uno de los requerimientos prioritarios para la dominación de estos pueblos era quebrar la lógica de desplazamiento estacional, apuntando a la sedentarización de los grupos. Para ello se creó una línea de reducciones (pueblos de indios) que cumplía un doble propósito: por una parte permitía 
consolidar las campañas militares de control territorial hacia el interior del monte y por otra debía funcionar como contención para frenar ataques indígenas a los poblados españoles.

Hacia 1760 existían siete reducciones en las jurisdicciones de Jujuy, Salta y Santiago del Estero, cuya localización geográfica era fundamental para resguardar la ruta de intercambio comercial del Río de la Plata con el Alto Perú. La organización de las reducciones en manos de los jesuitas permitió que en poco tiempo se conformaran en importantes centros de producción ganadera y agrícola, que se comercializaban en los poblados españoles e incluso con el área andina (Vitar, 1996). Este modelo se basaba en la utilización de fuerza de trabajo indígena, que eran "reclutados" por la fuerza a través de incursiones militares al interior del monte, para luego asentarlos en las reducciones, donde además de participar de la vida productiva recibían educación religiosa en un intento de "civilizarlos" en forma compulsiva.

El camino a la sedentarización implicaba una radical transformación de su modo de subsistencia cazador-recolector; sin embargo estas prácticas no fueron abandonadas en forma tajante, sino que se trató de un proceso gradual lleno de avances y retrocesos. Coexistía por una parte la necesidad de valorizar negativamente estas actividades a partir de una serie de valores morales respecto de aquello que es "trabajo" y "esfuerzo" y aquello que no lo es (p.e. cultivar lo era y recolectar no); con la necesidad de obtener alimentos frescos dado el marco de aislamiento fronterizo en el que se encontraban las reducciones respecto del "mundo colonial". Esto hacía que ciertas actividades fueran admitidas mientras otras se sancionaban estrictamente, en un intento por regular la relación con los grupos reducidos, dentro de un marco de relaciones interétnicas sumamente precario, donde los españoles estaban lejos de ejercer plenamente la dominación de sus posesiones. Los misioneros intentaban por sobre todo que los indígenas no volvieran "al monte", ya que en general esta circunstancia era aprovechada para escapar y abandonar la reducción.

Las prácticas de recolección de la algarroba nos permiten dar cuenta de interesantes matices asociados a este proceso. Si bien los europeos reconocían el enorme valor alimenticio que tenían estos productos y su centralidad para la subsistencia de los indígenas; lo cierto es que eran prácticas fuertemente estigmatizadas, ya que a los ojos de los conquistadores representaban la prueba fehaciente de la inmoralidad del modo de vida indígena. La economía nativa se leía desde la moral europea. 
Estas prácticas de recolección implicaba adentrarse en el monte, con el consiguiente riesgo que los indígenas aprovecharan para regresar a sus comunidades. Pero además elaboraban una bebida alcohólica obtenida de la fermentación de las vainas mezclada con agua ${ }^{9}$. Como señala Vitar (1996) los jesuitas intentaban controlar el consumo de esta bebida, ya que inducía a caer en masivas "borracheras", que desde la óptica de los europeos, representaba una clara manifestación de la "vida licenciosa" a la que se entregaban estos indígenas (ver Figura 2). La contradicción puede apreciarse en este fragmento:

"La celebración de fiestas en las épocas que se recogía su fruto, la algarroba, eran frecuentemente definidas desde el mundo colonizador como "borracheras"; "En tiempo de la algarroba es universal y continua la borrachera entre los indios" (Vitar, 1996:68-69) ${ }^{10 .}$

\section{Figura 2:}

"Sus ceremonias durante el beber en exceso". Ilustración de Florián Paucke. Banco de imágenes "Florián Paucke" 2006. Archivo General de la Provincia de Santa Fe.

\footnotetext{
$9 \quad$ La fructificación del algarrobo sucede en un corto período que generalmente comienza a fines de noviembre y finaliza a fines de enero. Este evento coincide con el inicio de la época húmeda y marca la finalización del extenso período seco (de unos 6/8 meses sin precipitaciones en el sector oeste de la región chaqueña). Esto también se asocia al inicio de un período de abundancia determinado por la fructificación de otras especies arbóreas, el incremento de la caza y la pesca, etc.

${ }^{0}$ El encomillado pertenece a una referencia introducida por la autora: Carta del Padre Andreu al Procurador General de la Compañía de Jesús. Miraflores 22-11-1757. Ms. ํㅜ 18.577 BNM.
} 


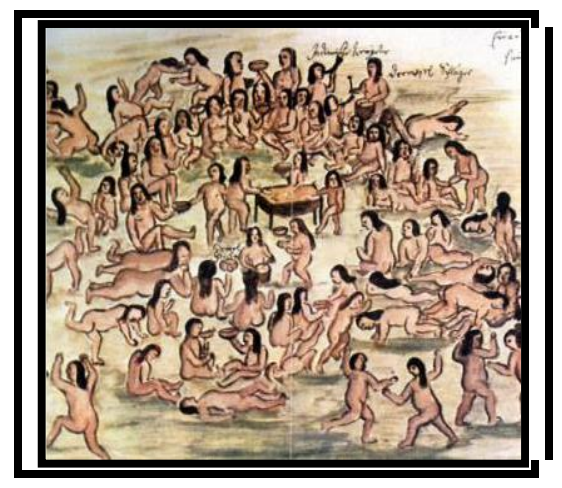

Como ya señalamos, los españoles asociaban el desarrollo de estas celebraciones con una merma significativa en la "docilidad" de los grupos indígenas, ya que frecuentemente eran seguidas de deserciones masivas e incluso ataques de estos grupos a las reducciones que los jesuitas intentaban establecer sin demasiada suerte en la llamada "frontera del Tucumán" (Op.cit., 1996:110). Pero aquello que los europeos caracterizaban despectivamente como "borracheras" eran en realidad instancias rituales de establecimiento y legitimación de las jefaturas y alianzas tribales, y por tanto prácticas simbólicas fundamentales en la dinámica social de estos pueblos en una etapa donde estaban enfrentados bélicamente con los españoles. El afán de alcanzar una dominación efectiva por parte de estos últimos, indicaba la necesidad de reprimir y desestructurar estas prácticas y para ello desvalorizarlas haciéndolas pasar como eventos pecaminosos y remarcando sus características más chocantes para el ojo de la corona y la iglesia. Esto se tradujo en una constante presión prohibitiva sobre el desarrollo de los festejos rituales asociados a la fructificación del algarrobo:

"Los bosques del chaco estaban atestados de algarrobos pero en la región de la treinta y dos reducciones no se veía uno solo de estos árboles. Los jesuitas decidieron no llevarlo a las misiones por una actitud de "ecología evangélica" para evitar que los clanes se emborrachasen. $Y$ ello a pesar que los mismos jesuitas hablaban de las maravillas de salud que provocaba la algarroba”. (Rosenzvaig, 1996:190)

Pese a que podríamos pensar que sucedía lo mismo con la recolección de otro recurso como la miel y la elaboración de guarapo (bebida alcohólica producida con la fermentación de la miel), debemos apuntar lo señalado por Vitar a este respecto: 
"La operación de extracción de miel se conocía por entonces con el nombre de meleada, actividad que durante la etapa reduccional se toleró -al contrario de los que ocurrió con otros hábitos alimenticios chaqueños-, por ser de gran utilidad para el comercio colonial..." (Vitar; 1996:68)

En efecto y al contrario de lo que sucedía con la algarroba, la miel silvestre representaba una moneda de cambio sumamente valorada en toda la región, ya sea como elemento de intercambio con los diferentes grupos étnicos chaqueños como también en relación a la dinámica comercial colonial entre el Río de la Plata y el Alto Perú. Junto con las maderas nobles representaba una de las principales riquezas nativas que podían ser objeto de explotación sistemática por parte de los conquistadores. La algarroba no corrió la misma suerte, excluida de los bienes nativos comercializables resistía el embate de la mirada utilitaria que convertía la naturaleza en mercancías, representando además un elemento que mantenía viva la práctica de aquellos saberes nativos enrolados en una "ecología arcaica", desde donde los pueblos chaqueños intentaron resistir la dominación colonial. Una dominación que como dice Rosenzvaig, implicó como primer objetivo la desestructuración de la estrecha relación ecológica que estas étnias mantenían con los ecosistemas chaqueños, y en tal sentido: “...las voces del algarrobo fueron las primeras en sentir el amordazamiento" (1996: 193)

\section{Segundo Momento: De los usos y saberes indígenas a los criollos en el centro-oeste formoseño.}

La dominación de los pueblos originarios del Chaco se consolidó recién hacia principios del siglo XX. Aquellos que sobrevivieron a la campaña de exterminio llevada a cabo por el ejército argentino para habilitar tierras y mano de obra barata al capital agrícola, fueron confinados en misiones y reducciones localizadas en tierras marginales. Sin la posibilidad de acceder libremente a territorios extensos, requisito indispensable para desarrollar un modo de vida cazador-recolector, fueron utilizados principalmente como mano de obra barata destinada a ingenios azucareros y otros cultivos industriales como el algodón, que comenzaban a ser impulsados en esta región (Gordillo, 2010 y Trinchero, 2000).

En la actual provincia de Formosa, las tierras fueron acaparadas por representantes de la pequeña oligarquía local y algunos funcionarios porteños, junto con ingenieros del ferrocarril (ramal Embarcación-Formosa) y cuadros militares de la campaña al chaco. Las tierras 
remanentes fueron destinadas a planes de colonización con migrantes europeos que no resultaron del todo exitosos, por lo que primó su ocupación espontánea por campesinos criollos provenientes de las provincias limítrofes y también del vecino Paraguay (Carenzo, 2004).

Una de las principales corrientes migratorias de población criolla ingreso por el oeste, desde las provincias de Salta y Santiago del Estero, ocupando progresivamente territorios pertenecientes a la subregión que hoy denominamos "chaco seco"11. Estas tierras se caracterizaban por su escasa aptitud agrícola, pero disponían de extensos pastizales, que eran muy valorados por estos criollos dedicados a la cría extensiva de ganado vacuno (De la Cruz, 2000).

Las dinámicas de contacto que se fueron desarrollando entre indígenas y criollos, fueron estableciendo una compleja trama relacional, atravesada por estereotipos asociados con la diferenciación étnica, de género y de clase, entre otras, las cuales perduran hasta hoy en día. Esto complejos contextos interétnicos, históricamente basados en el intercambio de bienes, la implementación de mano de obra y la conformación de matrimonios mixtos, pone de manifiesto cómo buena parte de los saberes de los pueblos originarios en relación al aprovechamiento de un ambiente riguroso como el chaco seco, se fueron incorporando al modo de subsistencia de los pobladores criollos. Un claro ejemplo de ello está representado por el uso de la algarroba en sus prácticas alimentarias.

La perspectiva desarrollada por el antropólogo Marvin Harris (1991) para comprender la variabilidad presente a nivel de las prácticas de alimentación humana, aporta un enfoque interesante para dar cuenta de este momento en la trayectoria social de la algarroba. Siguiendo a este autor, podemos señalar que las preferencias alimentarias de un grupo social en particular guardan estrecha relación con las limitaciones y oportunidades ecológicas que presenta un determinado territorio, de modo tal que la elección de determinados componentes está basada en razones prácticas, incluyendo como base de la dieta aquellos alimentos que resultan más accesibles, más fáciles de producir y/o más rendidores. En efecto, las restricciones ambientales para el desarrollo de cultivos en el área del chaco seco, favorecieron el desarrollo de una ganadería extensiva de bovinos y caprinos, como principal modo de subsistencia. Los cultivos tuvieron una importancia menor, restringiéndose básicamente a la producción de distintas

\footnotetext{
$1 \quad{ }^{1}$ El "chaco seco" abarca principalmente el norte de Santiago del Estero y este de Salta y oeste de las provincias de Chaco y Formosa, caracterizada por la ausencia de precipitaciones durante la mayor parte del año (menos de $800 \mathrm{~mm}$ anuales, concentrados en el verano).
} 
variedades de zapallos y porotos, esto hizo que la dieta de estas poblaciones criollas se estructure en base al predominio del consumo de proteínas cárnicas, con muy escasa presencia de alimentos vegetales de cultivo.

Sin embargo, sabemos que las especies de plantas domesticadas no son las únicas existentes, ni mucho menos el grupo más diverso de vegetales utilizados por el hombre para su alimentación, diversas culturas han elaborado estrategias adaptativas en base al aprovechamiento de una amplia variedad especies vegetales presentes en los ecosistemas, especialmente en bosques y selvas (Clay, 1988). Como vimos en el momento anterior, para las etnias que habitaban los bosques secos chaqueños, la fruta del algarrobo representaba un alimento clave. Siguiendo la perspectiva de Harris (1991), podemos señalar que efectivamente la algarroba presentaba una "relación de costes/beneficios prácticos" más eficiente en términos energéticos que los vegetales de cultivo. Su obtención se realiza mediante recolección, lo cual representa un "ahorro" en relación al esfuerzo productivo doméstico destinado al cultivo de vegetales. Así mismo, tanto la abundancia de esta especie, como su alta productividad (promedia entre 50 y $100 \mathrm{~kg}$ de frutos anuales/árbol) permite que su recolección sin necesidad de recorrer grandes distancias e incluso circunscribiéndose a unos pocos ejemplares cercanos. Sumado a esto resulta una actividad de bajo impacto en el ecosistema, ya que su obtención no requiere su tala, permitiendo el aprovechamiento del recurso a perpetuidad. Como mencionamos constituye un alimento integral, que concentra buena parte de los nutrientes básicos incluyendo azúcares naturales poco presentes en los vegetales cultivados que se obtienen en la zona. Finalmente puede conservarse y consumirse en la estación seca, cuando escasean otras fuentes de abastecimiento de esos nutrientes. Así, la incorporación de la algarroba en el patrón alimentario de los pobladores criollos, se expresa ya sea a través de su consumo directo de las vainas, como en una variedad de preparaciones tradicionales elaboradas con sus frutos, tales como patay, bolanchao, arrope, añapa y aloja (Demaio et.al., 2002).

Si bien su rol en la alimentación es central, la importancia que fueron adquiriendo los algarrobos en la vida de estas poblaciones campesinas no solo se deriva de sus beneficios en términos alimentarios, sino que además guarda estrecha relación con su condición de especie multipropósito, ya que también satisface necesidades de salud, construcción de infraestructura productiva y vivienda e incluso vestimenta (Demaio et al., 2002; Scarpa, 2001 y Galera, 2000).

A lo largo de este recorrido hemos puntualizado las múltiples razones que hacen que la algarroba ocupe un lugar central en el modo de subsistencia de los pequeños productores 
criollos del chaco. Sin embargo, la literatura advierte sobre una tendencia relacionada con el abandono progresivo de prácticas de producción y consumo de frutos silvestres del monte y su reemplazo por alimentos industrializados (Charpentier, 1998; Arenas, 2003; Scarpa, 2000 y Demaio et.al., 2002). En este sentido, el análisis que realizamos de la experiencia desarrollada por la ONG GESER en Ibarreta (Formosa) respecto del rescate y revalorización del uso de la algarroba puede ayudarnos a comprender el por qué de este fenómeno.

\section{Tercer momento: La algarroba a través de tres generaciones de campesinos formoseños}

A partir de este punto vamos a focalizar la reconstrucción de la trayectoria de la algarroba a través de las prácticas y representaciones presentes en grupos criollos de Ibarreta (Provincia de Formosa), relevadas a través del trabajo de campo efectuado durante las "algarrobeadas" realizadas entre 2003 y $2009^{15}$. La conformación del sector campesino en Ibarreta es heredero de este heterogéneo entramado sociocultural, por lo cual a través de las entrevistas realizadas nos fue posible retrotraernos históricamente algunas generaciones atrás, para poder reconstruir las trayectorias de estos grupos en relación al aprovechamiento de la algarroba. En tal sentido debemos tener en cuenta que aquellos entrevistados promediaban los 50 años, presentando una relación de parentesco directo con aquella primera generación de pobladores "criollos" que se asentaron en esta zona de la provincia.

\section{Algarroba, ambiente y genealogía familiar:}

Una primera observación que se deriva de las entrevistas realizadas es que existe una fuerte relación entre la genealogía de las familias de campesinos criolla y su relación con la algarroba. Aquellos sujetos cuyos antepasados provenían del "oeste", es decir de la zona del chaco seco localizada en Salta y Santiago del Estero, son quienes presentan un mayor conocimiento de los usos humanos vinculados a la algarroba, incluyendo nombres y procedimientos de las

$1 \quad{ }^{5} \mathrm{La}$ "algarrobeada" indica para estos grupos el proceso integral de recolección y procesamiento de la algarroba, que en la zona de Ibarreta comienza hacia fines de noviembre y finaliza a principios de febrero. Debemos señalar que esta actividad fue impulsada por la acción de la ONG GESER como parte de una línea de investigación y desarrollo de propuestas productivas alternativas basadas en el uso de Productos Forestales No Maderables (PFNM) provenientes del monte nativo. En tal sentido, los pequeños productores criollos participantes comenzaron a realizar esta actividad en forma sistemática a partir del trabajo conjunto con GESER sobre esta temática a partir del año 2004. 
preparaciones. En contraste, quienes descienden de migrantes del área de influencia guaranítica (principalmente Paraguay y Corrientes) no contaban con un saber especializado al respecto. En general conocen que con los frutos del algarrobo es posible elaborar alimentos para consumo humano, pero no refieren a estos como parte de las prácticas de alimentación familiares en el pasado reciente.

Tal como señalamos anteriormente, las condiciones ecológicas influyen en el proceso de conformación de las preferencias alimentarias de los grupos humanos. En la región chaqueña se evidencia un gradiente climático muy marcado, determinado principalmente por el nivel de precipitaciones registrado: desde el oeste seco hasta el este húmedo (de 600 a $1.200 \mathrm{~mm}$ anuales respectivamente). Este gradiente aporta también a la configuración del paisaje y la composición florística y faunística asociada. Hacia el este aumenta significativamente el nivel de precipitaciones, por lo cual encontramos ecosistemas más biodiversos, mientras que hacia el oeste disminuye esta proporción. Los algarrobos presentan una gran versatilidad por cuanto están presentes tanto en el chaco seco como en el húmedo, sin embargo como pueden adaptarse mejor que otras especies al stress hídrico, su presencia es dominante en la composición forestal de los bosques nativos del oeste, pero no en los del este (Galera, 2000). Esto se traduce en una importancia diferencial de la fruta del algarrobo en las prácticas alimentarias de estos grupos, por cuanto los migrantes provenientes de las zonas húmedas contaban con una mayor diversidad de alimentos vegetales frescos principalmente verduras y frutas, tanto cultivadas como silvestres. Estas constituían fuentes de obtención de azúcares mucho más accesibles y diversas que la algarroba (desde frutas frescas de árboles nativos, hasta el cultivo de caña de azúcar). En cambio, para los grupos localizados en el oeste la algarroba constituía la forma más abundante y accesible de obtención de glucosa, entre otros nutrientes básicos.

En tal sentido, la dieta mucho más variada de los grupos provenientes del este, se correspondía con el desarrollo de sistemas de producción de alimentos diversificados. En cambio, aquellos grupos que debieron adaptarse a condiciones ambientales más rigurosas, y por ende cuyos sistemas productivos eran menos diversificados, presentaban una mayor dependencia respecto del aprovechamiento de algunos recursos silvestres para conseguir aquellos nutrientes que no podían obtener del cultivo (la glucosa obtenida fundamentalmente de la miel y la algarroba).

El siguiente pasaje de una de las entrevistas realizadas sitúa este proceso en el contexto de la ocupación reciente de Ibarreta por parte de población criolla, cuando estos migrantes carecían 
aún de una infraestructura productiva adecuada, por cuanto eran más vulnerables a las rigurosidades del medio:

“....Mi padre contaba que cuando vinieron para acá... él era chico, porque la familia de ellos venían de chaco ...allá por el impenetrable, ...bueno, ellos no tenían nada ....imaginesé.... esto era pampa de pastizales y monte así...en islas por todos lados...(...) ellos sabían ocupar la algarroba, con eso me contaban que se salvaron en las sequías grandes (...) todavía cuando vivía mi abuela se hacía el patay, el bolanchao, la añapa pero ya después ya no se hizo más nada". (Productor, 42 años, Colonia Ismael Sánchez).

En este caso el conocimiento acerca del uso de la algarroba que portaban estos grupos provenientes del oeste, favoreció el desarrollo de estrategias adaptativas en las nuevas áreas de poblamiento a partir del empleo de recursos del monte para la alimentación humana, siendo especialmente importantes durante las primeras sequías extraordinarias a las cuales estas familias tuvieron que enfrentarse. Sin embargo, como se evidencia también en este pasaje de la entrevista, debemos remarcar que los patrones de alimentación de una sociedad determinada presentan una dinámica de transformaciones favorecida por cuestiones de índole socioeconómica, cultural y política. En algunas circunstancias estos cambios se producen en forma relativamente acelerada, tal como se desprende de este relato, ya que en tan solo dos generaciones una de las principales prácticas alimentarias de los grupos asentados en esta zona (consumo humano de algarroba) estaba completamente olvidada.

Esta misma referencia al consumo de algarroba como una práctica del pasado, pero que no está presente en la actualidad, se repitió en prácticamente todas las entrevistas en las cuales se evidenciaba un cierto conocimiento del uso de este fruto para la alimentación humana. En efecto, el testimonio de uno de los técnicos de la ONGD que trabajó en el proyecto del rescate y revalorización del uso de la algarroba es muy representativo de esta situación:

"Para una de las primeras actividades con los campesinos donde tratamos el tema de la algarroba, hicimos unas galletitas dulces con un poco de algarroba que habíamos juntado de prueba y las ofrecimos en la reunión. ...pensando que nos las iban a tirar por la cabeza! ...galletitas de algarroba hechas por un grupo de porteños pensábamos nosotros!. Sin embargo, el resultado nos dejó sorprendidos ...para muchos de ellos era la primera vez que probaban algo con algarroba, sabian que se usaba, pero nunca lo habian probado!" (Técnica de GESER). 
Ninguno de los aspectos que trabajaremos a continuación puede explicar por si solo el complejo proceso de cambios evidenciados en el patrón alimentario de estos grupos, cuyo tratamiento profundo excede por mucho el esbozo aquí planteado. Sin embargo creemos que el análisis de su relación con las profundas transformaciones materiales y simbólicas en sus sistemas productivos y con la degradación de sus condiciones de vida, pueden ayudarnos a comprender el por qué del abandono y/o reemplazo progresivo del consumo de algarroba entre estos pobladores criollos de Ibarreta. Los siguientes puntos expresan algunas hipótesis de trabajo que pueden servir para guiar una investigación más amplia sobre este proceso.

\section{La ideología del progreso y el pasaje de la recolección en el monte al cultivo en la chacra:}

Siguiendo el enfoque de análisis de las condiciones materiales en las que se sustenta un determinado modo de subsistencia, debemos señalar que efectivamente aquellos grupos provenientes de la zona más árida del chaco, encontraron en la zona Ibarreta la posibilidad de acceder a tierras de mayor aptitud agrícola, dentro de un ambiente caracterizado por un mayor nivel de precipitaciones (unos $1100 \mathrm{~mm} /$ anuales en promedio).

Por otra parte tomaron contacto con estos otros grupos poblacionales que habían desarrollado sistemas productivos diferentes, en los cuales la agricultura ocupaba un lugar central en la provisión de alimentos para la familia. Particularmente incorporaron una amplia variedad de preparaciones basadas en el uso del maíz y la mandioca que se generalizaron rápidamente entre los pobladores locales. De esta forma, la dinámica social estructurada en torno a la conformación de las colonias rurales con poblaciones de diversos orígenes, favoreció el intercambio de saberes y técnicas entre ambos grupos, permitió que se desarrollen nuevas capacidades en cuanto a los sistemas productivos ganaderos y agrícolas; así como en el desarrollo de nuevos hábitos alimentarios.

Posteriormente a partir de la década del 30 en adelante, desde el Estado se inició una política deliberada de promoción de producción agrícola vinculada al cultivo de fibra de algodón en toda la zona del chaco. El boom algodonero representó para estos productores campesinos la posibilidad de obtener apoyo en materia jurídica, técnica y financiera para consolidar sus sistemas prediales (Carenzo, 2004). 
Todos estos factores coadyuvaron para que estos criollos principalmente ganaderos reconvirtieran sus planteos productivos, otorgando un lugar preeminente a la actividad agrícola vinculada al cultivo de fibra. De este modo, el algodón se estableció en sus economías domésticas como principal actividad de renta. Sin embargo este desarrollo de la actividad agrícola no se circunscribió a este cultivo únicamente, ya que el aprendizaje de nuevas destrezas, la mecanización de sus explotaciones y la consolidación de la infraestructura predial (cercos, represas, etc), favorecieron el desarrollo de cultivos de huerta y chacra destinados al consumo doméstico. En tal sentido, este proceso pudo derivar en un incremento del consumo doméstico de vegetales cultivados como maíz, mandioca, batata, porotos, zapallos y calabazas, desplazando progresivamente aquellas prácticas basadas en la recolección de frutos del monte como fuente de nutrientes origen vegetal, tales como la algarroba.

Ahora bien, este proceso de transformación estructural de los procesos productivos campesinos no solo involucró aspectos materiales, sino también simbólicos de gran importancia para nuestro análisis. Puntualmente nos referimos a que el accionar del Estado en este sentido, constituía un componente central dentro de intento mucho más vasto de imponer un "proyecto civilizatorio" en una región todavía marginal dentro del proceso de constitución del Estado nación, donde el control estatal era aún deficiente.

Desde la visión de las elites dominantes, este proyecto "modernizador" debía apoyarse en la búsqueda de crecimiento económico vía aplicación de la racionalidad tecnológica del capitalismo a la producción agraria. Esta ideología dominante, basada en el utilitarismo económico como fundamento axiológico, se fue imponiendo progresivamente sobre otras formas locales de concebir la relación de los grupos humanos con la producción y la naturaleza, que habían sido desarrolladas tanto por los grupos indígenas como por los campesinos criollos. Si bien la implementación de este proyecto no resultó tal cual se había propuesto, ya que aquello que buscaba ser impuesto fue también resistido y fundamentalmente resignificado, lo cierto es que en términos generales y con el correr del tiempo, la población criolla fue internalizando esta forma de entender, desarrollar y representar sus propias prácticas productivas.

Quizá uno de los ejemplos más significativos a este respecto corresponde a las transformaciones evidenciadas en torno a las prácticas y representaciones criollas vinculadas al bosque nativo. A grosso modo y esquematizando para facilitar la comprensión de una realidad compleja, ambigua y contradictoria, podemos señalar que en menos de 50 años el status asignado a estos ecosistemas, evidencia un recorrido que va desde el predominio de una visión que reconoce al 
monte como espacio vital humano, como dador de recursos para la reproducción humana (abrigo, alimento, etc); a otra donde prima la representación de su exterioridad respecto al mundo humano, asumiendo una condición de obstáculo a la producción y por ende al progreso material de la sociedad. La necesidad de habilitar tierras para uso agrícola, implicó el desarrollo de una visión del monte como espacio marginal, "improductivo" desde la lógica de valorización del capital agrario. Esta construcción permitía legitimar el reemplazo de los ecosistemas de bosque en agrosistemas destinado al desarrollo de cultivos intensivos.

En este contexto, el aprovechamiento de la algarroba volvía a representar-como en tiempos de la colonia- una forma "primitiva" de relacionamiento con el medio. Las prácticas culturales asociadas a la recolección eran construidas nuevamente a partir de categorías morales negativas que las oponían al cultivo: Mientras que las primeras representaban el aprovechamiento de un bien sin la mediación del esfuerzo productivo (actitud oportunista); las segundas se instituían como modelo de la planificación del esfuerzo humano en pos de un objetivo productivo, en la cual la cosecha oficiaba como "merecida" recompensa (actitud proactiva). Esta idea es expresada en el testimonio de una coordinadora del grupo de jóvenes de las colonias agrícolas que participó en las algarrobeadas realizadas en Ibarreta, donde justamente comentaba la actitud reacia de muchos padres a que sus hijos participen en la experiencia:

“...acá en la colonia se pensaba que juntar algarroba era cosa de hambrientos, nos decían que parecíamos aborígenes, que porque no hacíamos otra cosa..." (Productora, 38 años, Colonia Ismael Sánchez)

A nivel del imaginario social local, el trabajo agrícola representaba el camino hacia el progreso y el bienestar de la sociedad moderna; en cambio, las prácticas de recolección remitían al "antiguo" mundo indígena. A nivel local la distancia social existente entre gringos, criollos e indígenas se hacía cada vez más amplia y exacerbada. En tal sentido pensamos que en forma progresiva y casi inadvertida, el consumo de algarroba y de otros bienes alimenticios obtenidos a través de la recolección, adquirieron un marcaje moral negativo del cual era preciso comenzar a diferenciarse.

Como podemos apreciar, el campo de "lo alimentario" resulta un ámbito privilegiado para dar cuenta de esta incidencia de criterios morales en la construcción social de representaciones sobre las prácticas productivas. Las formas efectivas que asume la alimentación del grupo familiar expresan una serie de valoraciones sociales acerca de su status en la estructura social 
local. De aquí que tanto la desvalorización de un modelo de alimentación basado en prácticas de recolección, como la revalorización del esfuerzo productivo como mediación previa y obligatoria del acto de consumo (modelo agrícola), reflejan una serie de representaciones que legitiman o no un modelo de sociedad dominante: en el caso puntual de la algarroba implicó el pasaje de lo aleatorio a lo previsible. La alimentación de la familia ya no podía depender de aquello que la naturaleza pueda ofrecer; sino de la voluntad y la capacidad del hombre por dominar y transformar la naturaleza, a través de una aplicación cada vez mayor de la ciencia y la técnica al hecho productivo.

\section{Abandono de alimentos tradicionales y remplazo por alimentos industrializados}

En forma complementaria el abandono y/o reemplazo de alimentos como la algarroba en sus dietas cotidianas, estos grupos fueron incorporando nuevas prácticas de consumo, centradas en productos industrializados que más allá de su calidad nutricional proveían la marca de un status social diferente. Como mencionamos anteriormente, la mayoría de los entrevistados que hicieron referencia al uso histórico de la algarroba por parte de sus padres y abuelos, no incorporaban este alimento dentro de las prácticas alimentarias de sus propios núcleos domésticos. El relato de una de mujer entrevistada es elocuente al respecto:

"Yo recuerdo que sabian darnos la algarroba tostada mezclada con leche... así como el nesquick, viste?... a nosotros que éramos chicos, de más nos gustaba... (...) no, los míos no llegaron nunca a probarla, a ellos no los sacas del polvo para preparar chocolate..." (Productora, 43 años, Pueblo de Ibarreta)

A través del recuerdo de su infancia aparece esta referencia a una versión de la añapa, donde la algarroba era mezclada con leche. De esta forma se obtenía un alimento de agradable sabor, ya que su preparación con harina tostada realza la nota achocolatada que poseen estos frutos.

Como señalamos anteriormente, este ejemplo del reemplazo de la algarroba por la generalización del consumo de alimentos industrializados se produce en un contexto signado por la creciente monetarización de sus economías domésticas, en un contexto de degradación de su situación socio-productiva en general (Carenzo, 2004). Si bien en un principio este mayor acceso al dinero estuvo dado por la orientación de su producción hacia los cultivos de renta como el algodón, en las últimas décadas ha cobrado una importancia creciente la venta de su fuerza de trabajo en ocupaciones poco calificadas, ya sea en otras explotaciones de la localidad 
o bien migrando hacia otros ámbitos urbanos y rurales. En ambos casos se produjo una mayor dependencia del mercado, tanto de productos como de trabajo como requisito para garantizar la reproducción social de estas unidades. Esta dependencia afecta especialmente la capacidad productiva de las mismas, ya que implica por ejemplo la ausencia temporal de los individuos económicamente activos que salieron buscar empleo fuera del predio. Al producir menos alimentos destinados al consumo familiar y disponer de mayor circulación de dinero, se incrementó la compra de bienes de consumo, que en el caso de los alimentos reemplazaron a otros que antes se producían localmente.

El caso de la algarroba es especialmente significativo ya que evidencia en forma tangible una tendencia preocupante en relación a la pérdida de diversidad en el patrón alimentario local. Aquellos productos provenientes de la recolección en el monte, como la algarroba, fueron las primeras manifestaciones de este proceso; sin embargo en los últimos años también está afectando a otros productos agrícolas tradicionalmente cultivados en la localidad, como el maíz amarillo y la mandioca. Ambos constituyen productos representativos de la dieta tradicional de estos grupos, sin embargo los datos obtenidos en el trabajo de campo indican cada vez son producidos por menos cantidad de familias. El maíz amarillo es el preferido para fabricar harina con la cual se elabora un plato típico denominado "sopa paraguaya", sin embargo su producción local es cada vez menor, siendo reemplazado por harina de maíz industrializada proveniente de pequeños establecimientos agroindustriales localizados en grandes ciudades como Resistencia (Provincia de Chaco). Aunque se reconoce su calidad deficiente, estos productos se obtienen a un precio económico en el pueblo, registrando una demanda creciente. Asimismo, es cada vez más frecuente el reemplazo de la mandioca, por la papa proveniente de la provincia de Buenos Aires, que se obtiene en forma regular durante todo el año en las verdulerías locales

Las principales explicaciones de los entrevistados respecto de los motivos de esta situación, se relacionan con los cambios en el régimen de precipitaciones, cuya irregularidad dificulta la planificación de la siembra, aumentando el riesgo de una producción fallida; así como también el elevado valor de la semilla (casi el doble que el maíz común) y con la dificultad para conseguir que esta semilla sea provista por organismos de apoyo técnico tanto provinciales como nacionales. Independientemente de la validez o no de estos argumentos, el resultado es el mismo: una creciente uniformización en el patrón alimentario local a partir de la generalización de un conjunto restringido de alimentos que entran en los circuitos de mercado masivo.

Pan para los hombres, algarroba para las vacas: 
El progresivo abandono de la utilización de la algarroba para la alimentación humana contrasta con su utilización en la alimentación animal. El consumo de frutos nativos por parte del ganado criollo, representa una práctica extendida sobre toda la región chaqueña, especialmente en el denominado chaco seco, donde incluso buena parte de la recolección de la algarroba tiene por objeto suplementar la escasa disponibilidad de pastos durante la época seca.

Todavía hoy en la zona oeste esta forma de alimentar el ganado está asociada a un conjunto de prácticas culturales que incluyen la recolección, el almacenamiento en trojas y el racionamiento para lograr su consumo diferido en el tiempo. Muy probablemente, al inicio de su poblamiento criollo, este tipo de prácticas también estaban generalizadas en la zona de Ibarreta, siendo introducidas por los primeros migrantes. Sin embargo, como se desprende de varias de las entrevistadas realizadas, parece que también esta práctica ha perdido vigencia:

"...cuando sale de la seca, la vaca está flaca... no tiene fuerza para hacer terneros, quedan preñadas y se mueren!, por eso es un espectáculo cuando frutea la algarroba, es como que ellas ya saben cuándo va a caer la fruta madura y se van disparando al monte para comer (...) y no sabe cómo se ponen, ....gordas! ....el cuero brilla!... le digo que es un espectáculo!'”(Productor, 68 años, Colonia Ensanche Sur).

En el marco de estos sistemas productivos y correlativamente con la desvalorización de su uso para la alimentación humana, la algarroba reafirmaba su importancia como insumo forrajero; debido principalmente a su alto valor nutricional y su costo nulo. Sin embargo, esta utilización también demostró una progresiva transformación ya que actualmente no se asocia a la realización de una recolección orientada a este fin, sino que se deja que los animales la aprovechen por sus propios medios, mientras deambulan libremente por los ambientes de monte.

$\underline{\text { Hacia la resignificación del uso de la algarroba en la actualidad: }}$

Los primeros esfuerzos volcados a recuperar la práctica de la recolección de la algarroba como una actividad organizada en forma colectiva en el ámbito de Ibarreta comenzaron en 2003. Acompañados por técnicos de GESER, unas cincuenta familias de campesinos criollos que ya venían participando en otros proyectos relacionados a revalorizar los ambientes de monte como espacios privilegiados para desarrollar una producción sustentable y diversificada. 
Al inicio de esta actividad la participación fue muy escasa, ya que no era considerada una actividad propia de criollos, sino de indígenas, por cuanto su puesta en práctica implicaba la posibilidad de ser socialmente estigmatizados en un medio donde la distancia social existente entre ambos grupos es muy marcada, pese a que buena parte del sector productores criollos se halla cada vez más pauperizado en sus condiciones de existencia. Por otra parte, se reconocía el valor forrajero de la algarroba, aunque sin asociarlo a una actividad productiva realizada por el grupo familiar. En tal sentido, los técnicos de GESER comenzaron a desarrollar una serie de capacitaciones teórico-prácticas relacionadas con la puesta en valor de los productos no maderables que podían obtenerse de los ambientes de monte, haciendo especial énfasis en aquellos frutos que servían para la alimentación humana y animal ${ }^{17}$. Estos espacios funcionaron como lugares de reflexión colectiva en relación a las representaciones que los campesinos tenían del monte y de sus recursos potenciales, permitiendo analizarlas críticamente en función de las prácticas concretas de uso de estos ambientes. Estas actividades servían de marco preparatorio para el desarrollo de las algarrobeadas al acercarse el mes de Noviembre. La experiencia práctica de realizar en conjunto la recolección, el secado y molido para obtener harina, y posteriormente elaborar alimentos con ella, resulto clave para fortalecer el reconocimiento y revalorización del rol de estos frutos en la dieta cotidiana doméstica.

En relación a esto, vamos a resaltar solo dos aspectos significativos para dar cuenta del proceso de resignificación de estas prácticas a nivel de las familias involucradas en esta experiencia: por una parte la recuperación de la algarroba como alimento y por otra su proyección como alternativa productiva en el marco de estas economías domésticas.

En relación al primer punto, resultó clave el trabajo sobre los recetarios vinculados a la algarroba, ya que si bien se recuperaron las preparaciones tradicionales, se puso especial énfasis en el desarrollo y adaptación de nuevas recetas que permitan incorporarla a un conjunto de preparaciones más "modernas". Para muchos representó una oportunidad para valorizar saberes pasados, que se creían perdidos para siempre, recuperando sus propias trayectorias familiares.

17 En estos espacios no solo se trabajó a partir de conceptos clave relacionados p.e. con la importancia del monte en los procesos ecológicos que permiten que la producción familiar se mantenga en el tiempo; sino que además se complementaba con la experiencia práctica, a través de recorridas en terreno, la recolección y el procesamiento de los diferentes frutos para elaborar harinas para el consumo humano y alimento balanceado para los animales domésticos. 
Por otra parte, resultó relevante la estrategia de incorporar el uso de la algarroba en nuevas recetas para elaborar panificados. El desarrollo de nuevas formas de uso permitió indagar en las propiedades nutricionales y organolépticas de la algarroba, por sobre las representaciones de ésta que remitían a lo "viejo y antiguo". De este modo se aprovechó la versatilidad de este insumo para fomentar la creatividad de aquellos que la elaboran, y buscaban nuevas formas de generar productos novedosos para el medio local.

El último punto, tiene que ver con la proyección de la producción de algarroba como alternativa productiva. En un primer momento, la experiencia con la algarroba estuvo circunscripta al abastecimiento familiar y a la comercialización de los pocos excedentes en el pueblo de Ibarreta. Sin embargo, año tras año la algarrobeada creció tanto en número de familias participantes como en cantidad de harina elaborada. Esto hizo que se comience a trabajar en un proyecto de comercialización de esta harina en un mercado más grande, pero que al mismo tiempo permitiera valorizar las condiciones socio-ambientales en las que el producto se elaboraba. El desarrollo de experiencias de comercio justo $^{18}$ en grandes ciudades del país (como Buenos Aires y Rosario) ofrecía un ámbito interesante para introducir la harina de algarroba producida en los montes formoseños. Debemos considerar que los productores criollos desconocían que la algarroba pudiera tener demanda en otras regiones y menos en esas ciudades, caracterizadas por el consumo generalizado de alimentos industrializados. Las familias criollas comenzaron a visualizar esta actividad como una alternativa productiva que permite aumentar el nivel de ingresos de la familia, fortaleciendo al mismo tiempo una estrategia diversificada:

“Antes se hacía aloja y el resto para los animales... ahora se puede hacer plata, rinde para tu bolsillo” (Productor, 53 años, Colonia Ismael Sánchez).

Más allá de la importancia que tiene para estas familias la recuperación de la harina en sus prácticas de consumo y de la posibilidad de incorporar una nueva alternativa productiva desde la

$1 \quad 8$ El enfoque del Comercio Justo apunta a lograr una producción sustentable en términos ambientales, económicos y sociales, que se corresponde con la idea de un consumo responsable incorporando valores éticos, sociales y ambientales, desde la cual se cree reconocer y valorizar las particularidades del contexto ambiental, económico y social en los que se producen los alimentos, estableciendo "nichos de mercado particulares" asociados a universos simbólico, que construyen la idea de "conexión de sentido" entre "identidades territoriales" y "consumidores responsables" (Carenzo, 2007). 
cual generar ingresos, queremos finalizar destacando la importancia de participar en un proceso colectivo que implica coordinar los esfuerzos de diferentes unidades productivas en pos de un objetivo común. El relato de la coordinadora del grupo de jóvenes destaca este proceso:

“...pese a vivir acá no le prestábamos atención a esta fruta, para eso nos sirvió empezar con esta experiencia... ahora sabemos cuando madura bien la fruta, que árbol carga mejor, el que tiene la fruta más gorda... todo eso nos sirve para planificar mejor el trabajo (...) ... esto empezó a cambiar cuando empezamos a comercializar y a ganar nuestra plata con esto (...) Además estamos apostando a romper el esquema de que todo se hace por separado, individualmente, así... cada uno aislado en su chacrita... acá estamos apostando al trabajo colectivo... que es la única esperanza acá en la colonia... ”(Productora, 38 años, Colonia Ismael Sánchez).

Especialmente para el grupo de jóvenes que participó activamente de esta experiencia, este aprendizaje de nuevas modalidades de encarar el proceso productivo representa una apuesta a futuro donde se expresa otra relación entre lo individual y lo colectivo, entre el saber ancestral y la experiencia contemporánea. La resignificación de las prácticas vinculadas a la algarroba adquiere de esta manera un sentido mucho más vasto e integrador, donde lo que se pone en juego no son ya las representaciones sociales sobre un bien de la naturaleza en particular, sino sobre su propio rol como parte de la juventud rural en la sociedad actual.

\section{A modo de reflexiones finales}

A través del presente trabajo pudimos aportar algunos elementos conceptuales y metodológicos que nos permitieron desarrollar un sintético análisis de las trayectorias sociales de la algarroba en el contexto territorial del Chaco. En tal sentido resaltamos la importancia de considerar en forma integrada los aspectos materiales y simbólicos presentes en estos recorridos del alimento a través de diferentes contextos sociales, económicos, políticos y culturales.

La identificación de determinados "momentos" significativos resultó de utilidad para contrastar las diferentes prácticas y representaciones vinculadas al uso de esta especie a lo largo de un recorrido que abarca tres siglos, donde se entrelazan situaciones de desvalorización, reconocimiento y recuperación en un proceso complejo que requiere un análisis multidimensional. 
Tal como se evidenció en el presente trabajo el patrón alimentario de un grupo determinado es resultado de un proceso sumamente dinámico, que incluye transformaciones que pueden ocurrir en unas pocas generaciones, como ocurrió con la algarroba entre los pequeños productores de Ibarreta. De este modo el análisis y reflexión acerca de estas prácticas concretas relacionadas al uso de los recursos, así como aquellas representaciones que las ligan con determinados significados socialmente construidos, constituye un esfuerzo central para el desarrollo de la Soberanía Alimentaria en nuestro país. Este concepto se diferencia de la Seguridad Alimentaria en un aspecto central, mientras este último está centrado en garantizar el acceso a los alimentos para toda la humanidad, el enfoque de la Soberanía Alimentaria incorpora además una cuestión central, ya que especifica que cada grupo social tiene el derecho a decidir cuál es el modelo de producción, distribución y consumo de alimentos que resulta más acorde a sus propios objetivos de desarrollo.

Específicamente en relación con la algarroba, esto implica trabajar a nivel de las familias de pequeños productores rurales sobre la resignificación de las prácticas de recolección de productos silvestres en el monte. De modo tal que es necesario recuperar las prácticas históricas para ponerlas en valor en un nuevo contexto social, esto es dar cuenta de las resignificaciones de las que es objeto por parte de los propios productores, evitando de este modo caer en un enfoque escencialista que termina inmovilizando la rica dinámica de creación y atribución de sentidos por parte de estos grupos. Es así que pretendemos que el presente trabajo aporte a desnaturalizar las relaciones que los grupos sociales establecen con aquello que consideran "alimento", entendiendo que ni las prácticas ni las representaciones aparecen ligadas a este de una vez y para siempre; sino que reconocen una trayectoria compleja y cambiante e históricamente determinada.

\section{Bibliografía}

ARENAS, P. 2003. Etnografia y alimentación entre los toba - nachilñamole\#ek y wichí lhuku'tas del Chaco Central (Argentina). 1a. ed. Buenos Aires.

BALAZOTE, A. y RADOVICH, J. C. 2000a. "Mapuches de Neuquen: conflictos en el orden economico y simbolico" - en: AA.VV. El resignificado del desarrollo. UNIDA, Buenos Aires

BOURDIEU, P. 1988. La Distinción. Criterios y bases sociales del gusto. Ed. Taurus. España. 
BRATICEVIC, Sergio. 2009. "Una aproximación territorial a la aplicación de proyectos de desarrollo en la cuenca media del río Pilcomayo: La ejecución del DIRLI en el oeste de Formosa" - en: Fronteras del desarrollo. Impacto social y económico en la cuenca del río Pilcomayo. TRINCHERO, H y BELLI, E. (Coord.). Ed. Biblos. Buenos Aires.

CARENZO, S. 2004. Procesos de articulación de economías domésticas campesinas y proyectos de desarrollo sostenible: el caso del Proyecto Vinal en la Provincia de Formosa Argentina. Tesis de Licenciatura, Facultad de Filosofía y Letras, UBA.

CARENZO, S. 2007. Territorio, identidad y consumo: reflexiones en torno a la construcción de nuevos paradigmas en el desarrollo - en: Cuadernos de Antropología Social. Trinchero, H; A, Balazote, A y S. Valverde (Edit.). N²6, pp. 125-143. FFyL - UBA.

CHARPENTIER, M. 1998. Valores nutricionales de las plantas alimenticias silvestres del norte argentino. INCUPO, Reconquista, Santa Fe, Argentina.

CLAY, J. 1988. Indigenous peoples ando tropical forest. Models of land use and management fron Latin America. Cultural Survival Report N²7. Cambridge.

CONTRERAS, J. 1993. Antropología de la alimentación. Ed. Eudema, Madrid.

DE LA CRUZ, L.M. 2000. ¿Qué pasó con los pastizales que vio Astrada?. Mimeo.

DEMAIO, P.; KARLIN, U.O. y MEDINA, M. 2002. Árboles nativos del centro de Argentina. Ed. LOLA, Buenos Aires.

DOMÍNGUEZ, D.; LAPEGNA, P. y SABATINO, P. 2002. Soberanía Alimentaria y Seguridad Alimentaria: problemas políticos y polisemia conceptual. Asociación Latinoamericana de Sociología Rural - ALASRU. VI Congreso. Porto Alegre.

FISCHLER, C. 1995. "Las funciones de lo culinario" - en: El (h)omnívoro. Ed. Anagrama. Barcelona. 
GALERA, F.M. 2000. Los Algarrobos: Las especies del género Prosopis (algarrobos) de América Latina con especial énfasis en aquellas de interés económico. FAO - SECyT, Universidad Nacional de Córdoba.

GORDILlO, G. 2010. Lugares del diablo. Tensiones del espacio y la memoria. Ed Prometeo. Buenos Aires.

GRAFFIGNA, M.L. 2005. "Trayectorias y estrategias ocupacionales en contextos de pobreza: Una tipología a partir de los casos" - en: Trabajo y Sociedad - Indagaciones sobre el empleo, la cultura y las prácticas políticas en sociedades segmentadas. $N^{\circ} 7$, vol. VI, junio- septiembre de 2005, Santiago del Estero, Argentina. ISSN 1514-6871

HARRIS, M. 1991. Bueno para comer. Ed. Alianza, México.

PAUCKE, F. S.J. 1942. Hacia allá y para acá (Una estada entre los indios mocobies 17491767). Traducción de E. Wernicke. Tucumán-Buenos Aires. Publicación del Instituto de Antropología del Departamento de Investigaciones Regionales - Universidad Nacional del Tucumán.

PIAGGIO, L. y SOLANS, A. 2009. “Alimentación, cultura e identidad" - en: Apunte de la Cátedra Antropología alimentaria. Instituto Universitario de Ciencias de la Salud - "H. Barcelo". Buenos Aires.

PINOTTI, Luisa. 2004. Aquellos tehuelches. Proyecto Editorial, Buenos Aires.

QUIROGA, L. 2010. Estrategias productivas en unidades domésticas campesinas en la localidad de Ibarreta, provincia de Formosa. Tesis de Licenciatura, Facultad de Filosofía y Letras, UBA.

ROSENZVAIG, E. 1996. Etnias y árboles. Historia del universo ecológico Gran Chaco. Ed. Casa de las Américas, Colombia. 614 pp.

SHIVA, V. 2003. Cosecha robada. El secuestro del suministro mundial de alimentos. Paidos. Buenos Aires. 
Papeles de Trabajo No 27 - Julio 2014 - ISSN 1852-4508

Centro de Estudios Interdisciplinarios en Etnolingüistica y Antropología Socio-Cultural

SCARPA, G. 2000. Estudio etnobotánico de la subsistencia de los "criollos" del chaco noroccidental argentino. Tesis Doctoral, Facultad de Ciencias Exactas y Naturales, UBA. Buenos Aires.

TRINCHERO, H.H. 2000. Los Dominios del Demonio. Civilización y Barbarie en las fronteras de la Nación: El Chaco central. EUDEBA. Buenos Aires.

VITAR, B. 1996. Guerra y misiones en la frontera chaqueña del tucumán (1700-1767). Biblioteca Historia de América. Consejo Superior de Investigaciones Científicas. Madrid, España. 372 pp. 